\title{
Simultaneous onset of idiopathic dilated cardiomyopathy in identical middle-aged twins
}

\author{
A G C Sutton, U Somasundram, J A Hall
}

\begin{abstract}
Summary
Idiopathic dilated cardiomyopathy is a primary myocardial disease which is characterised by left ventricular, or biventricular, dilatation and impaired contractility. The precise aetiology is unknown and the relative contribution of genetic and environmental factors is debated. We report two identical male twins of Caucasian origin with idiopathic dilated cardiomyopathy who presented within a few months of each other.
\end{abstract}

Keywords: idiopathic dilated cardiomyopathy; twins

Two identical male twins were born in 1937 . Both had unremarkable medical histories, with the exception of a hemi-thyroidectomy performed in the younger twin (by 20 minutes) for benign nodular goitre. In particular, neither twin had a history of hypertension, rheumatic heart disease, diabetes mellitus or any neuromuscular disorder. Neither took excessive alcohol or smoked tobacco. At no stage had either twin experienced anginal-type chest pain. Neither twin had previously received treatment with any cardiotoxic chemotherapeutic agents. The older twin had worked in the building industry, but there was no history of prolonged exposure to industrial toxins. There was a weak family history of ischaemic heart disease but not of cardiomyopathy.

The older twin presented in May 1995 with a one-week history of paroxysmal nocturnal dyspnoea. He was admitted to hospital. The findings on physical examination were an irregularly irregular pulse with a rate of 110 beats/min and a blood pressure of 140/80 $\mathrm{mmHg}$. The central venous pressure was elevated and auscultation revealed normal heart sounds with no gallop, a pansystolic murmur and bibasal inspiratory crepitations. Chest X-ray revealed a normal cardiac size without evidence of frank pulmonary oedema. The electrocardiograph confirmed atrial fibrillation with a ventricular rate of 113 and no evidence of ischaemia or prior myocardial infarction. Full blood count, thyroid function tests and biochemical profile, including cardiac enzymes, were normal. Serum ferritin was at the low end of the normal range. The patient was treated to good effect with digoxin, diuretics and warfarin. Subsequent echocardiography revealed mild dilatation of the left ventricle (end-systolic internal dimension $4.3 \mathrm{~cm}$, normal range $2.5-4.1 \mathrm{~cm}$; end-diastolic inter- nal dimension $5.7 \mathrm{~cm}$, normal range 3.5-5.6 $\mathrm{cm}$ ), incomplete co-aptation of the mitral valve cusps with an eccentric regurgitant jet and a dilated left atrium (diameter $4.0 \mathrm{~cm}$, normal $1.9-3.8 \mathrm{~cm}$ ). The calculated left ventricular ejection fraction was $40 \%$. The echocardiographic appearances of the mitral valve suggested regurgitation secondary to myocardial pathology rather than a primary valve disorder.

Despite the introduction of angiotensinconverting enzyme (ACE) inhibitors, the patient's symptoms worsened and he was referred to the regional centre for cardiac catheterisation. This revealed minor coronary artery disease, with a $50 \%$ lesion in the second obtuse marginal branch and $10 \%$ lesions in the mid-right coronary artery and mid-left anterior descending artery. There was grade III mitral regurgitation with a left ventricular ejection fraction of $40 \%$, end-diastolic pressure 18 $\mathrm{mmHg}$ and aortic pressure of $98 / 66 \mathrm{mmHg}$, mean $82 \mathrm{mmHg}$. There was moderate pulmonary hypertension, pulmonary artery pressure $44 / 18 \mathrm{mmHg}$, mean $30 \mathrm{mmHg}$. Histological examination of biopsy material from the left ventricle revealed subendocardial fibrosis, variation in myocyte size with some central vacuolation and no evidence of glycogen or iron storage abnormalities (figure). The findings were consistent with dilated cardiomyopathy.

The second twin presented in January 1996 with a short history of nocturnal cough and wheeze. This was associated with at least one episode of confirmed atrial fibrillation. He was admitted to hospital for investigation and treatment. Serial electrocardiographs confirmed paroxysmal atrial fibrillation and suggested left atrial dilatation. Echocardiography revealed left ventricular dilatation (end-systolic internal dimension $4.7 \mathrm{~cm}$, end-diastolic inter-

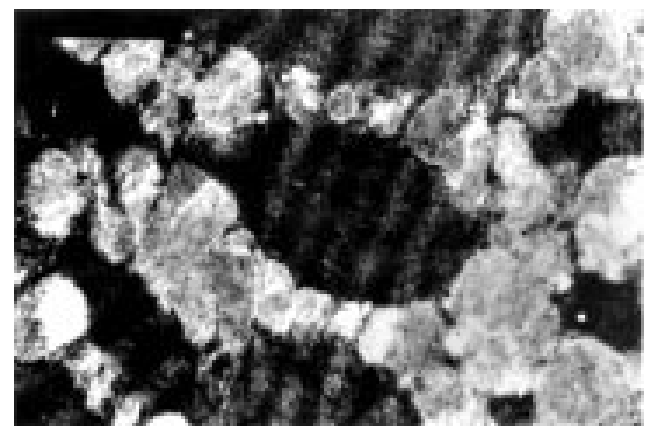

Figure Biopsy material from the left ventricle of the elder twin 
nal dimension $5.4 \mathrm{~cm}$ ), mild mitral regurgitation with a normal mitral valve appearances and dilatation of the left atrium (diameter 4.0 $\mathrm{cm})$. The calculated left ventricular ejection fraction was $32 \%$. There was mild left ventricular hypertrophy. Biochemical profile, thyroid function tests and full blood count were normal. Serum ferritin was at the low end of the normal range. Treatment was commenced with warfarin, diuretics, amiodarone and an ACE-inhibitor. He was referred to the regional centre for cardiac catheterisation and left ventricular biopsy. This revealed normal coronary arteries, a left ventricular ejection fraction of $38 \%$, end-diastolic pressure $2 / 12 \mathrm{mmHg}$ and aortic pressure of $112 / 65 \mathrm{mmHg}$, mean 82 $\mathrm{mmHg}$. Pulmonary artery pressure was $27 / 12$ $\mathrm{mmHg}$, mean $18 \mathrm{mmHg}$. Histological examination of a biopsy specimen from the left ventricle revealed fibrosis, variation in cell size and some cells with central degenerative vacuoles. The findings were consistent with dilated cardiomyopathy.

\section{Discussion}

Idiopathic dilated cardiomyopathy is not a rare condition. The estimated prevalence from studies in the US is 36.5 cases per 100000 of the population ${ }^{1}$ with males more commonly affected than females and Afro-Caribbeans more than Caucasians. ${ }^{2}$ The reported 5-year survival rates are $50-80 \%$, depending on the series. $^{34}$ The condition is currently the most common indication worldwide for cardiac transplantation. Proposed pathogenetic mechanisms resulting in the disease include familial and genetic factors, chronic viral infection with resultant cardiac myocyte damage, and dysfunction of the immune system with autoimmune destruction of cardiac myocytes. It would seem likely that a number of factors combine to produce clinical disease in susceptible patients.

In recent years it has become apparent that familial disease is more important than was previously thought. Michels et $a l^{5}$ studied 315 relatives from the families of 59 index cases with dilated cardiomyopathy, finding that $20.3 \%$ of index cases had an affected relative. In addition, $9.2 \%$ of healthy relatives with nor-

1 Codd MB, Sugrue DD, Gersh BJ, Melton LJ 3rd Epidemiology of idiopathic dilated and hypertrophic cardiomyopa-
thy. A population-based study in Olmsted County, Minnethy. A population-based study in Olmsted Count
sota, 1975-1984. Circulation 1989;80:564-72.

2 Coughlin SS, Szklo M, Baughman K, Pearson TA. The epidemiology of idiopathic dilated cardiomyopathy in a biracial community. Am f Epidemiol 1990;131:48-56.

3 Fuster V, Gersh BJ, Giuliani ER, Tajik AJ, Brandenburg RO, Frye RL. The natural history of idiopathic dilated cardiomyopathy. Am $\mathcal{A}$ Cardiol 1981;47:525-31.

4 Sugrue DD, Rodeheffer RJ, Codd MB, Ballard DJ, Fuster V, Gersh BJ. The clinical course of idiopathic dilated cardiomyopathy. A population-based study. Ann Intern Med 1992;117:117-23.

5 Michels VV, Moll PP, Miller FA, et al. The frequency of familial dilated cardiomyopathy in a series of patients with idiopathic dilated cardiomyopathy. $N$ Engl f Med 1992;326: $77-82$.

6 Keeling PJ, Gang Y, Smith G, et al. Familial dilated cardiomyopathy in the United Kingdom. Br Heart $\mathcal{7} 1995 ; 73: 417$ 21 .

7 Durand J, Bachinski L, Bieling L, et al. Localization of a gene responsible for familial dilated cardiomyopathy to chromosome 1q32. Circulation 1995;92:3387-9. mal left ventricular ejection fractions had increased left ventricular dimensions during systole or diastole. Keeling et $a l^{6}$ reported similar findings when studying 236 relatives from the families of 40 patients with dilated cardiomyopathy. In this study, 25 cases of dilated cardiomyopathy were identified among the relatives, of whom 22 were first degree relatives. The affected relatives all came from $10(25 \%)$ of the 40 families screened. Amongst the apparently healthy relatives, $37(18 \%)$ were found to have left ventricular enlargement.

The mode of inheritance in families with the condition is most commonly autosomal dominant. Genetic linkage analysis of a large family with familial dilated cardiomyopathy has indicated that the gene responsible for this condition is located on the long arm of chromosome 1 (1q32). ${ }^{7}$ However, four other specific gene loci for autosomal dominant dilated cardiomyopathy have also been described, ${ }^{8-11}$ indicating the genetically heterogenous nature of the condition. Autosomal recessive, ${ }^{12} \mathrm{X}$-linked recessive, ${ }^{13}$ and maternal inheritance through mitochondrial DNA have also been reported. ${ }^{14}$

To our knowledge, there has been only one published report of late-onset dilated cardiomyopathy in identical male twins. ${ }^{15}$ It is worth noting, however, that both these patients had maturity-onset non-insulin-dependent diabetes mellitus and one twin had hypertension.

The patients described here live close together in the same village. Therefore, it is possible that an environmental factor has played a part in the development of their similar cardiac conditions. In addition, the occurrence of dilated cardiomyopathy in members of the same family does not necessarily imply that the condition has a genetic basis. However, in the case of this pair of twins, the identical genetic profile and the onset of symptoms within a few months of each other would seem to imply that genetic factors in the aetiology of dilated cardiomyopathy are indeed more important than has been previously realised.

The authors acknowledge the assistance of Dr C Ritchie, Consultant Pathologist, Middlesbrough General Hospital, Middlesbrough.

8 Kass S, MacRae C, Graber HL, et al. A gene defect that causes conduction system disease and dilated cardiomyopathy maps to chromosome 1p1-1q1. Nat Genet 1994;7:54651 .

9 Krajinovic M, Pinamonti B, Sinagra G, et al. Linkage of familial dilated cardiomyopathy to chromosome 9. Heart Muscle Disease Study Group. Am f Genet 1995;57:846-52. 10 Olson TM, Keating MT. Mapping a cardiomyopathy locus to chromosome 3p22-p25. F Clin Invest 1996;97;528-32.

11 Bowles KR, Gajarski R, Porter P, et al. Gene mapping of familial autosomal dominant dilated cardiomyopathy to chromosome 10q21-23. F Clin Invest 1996;98:1355-60.

12 Mestroni L, Miani D, Di Lenarda A, et al. Clinical and pathologic study of familial dilated cardiomyopathy. Am $\mathcal{F}$ Cardiol 1990;65:1449-53.

13 Berko BM, Swift M. X-linked cardiomyopathy. $N$ Engl $\mathcal{f}$ Med 1987;316:1186-9.

14 Zeviani M, Gellera C, Antozzi C, et al. Maternally inherited myopathy and cardiomyopathy: association with mutation in mitochondrial DNA tRNA.[Leu)(UUR] Lancet 1991;338: mitoch.

15 Twidale N, Kipperman RM, Whitehead AW, Blaker AM, Galichia JP. Late-onset idiopathic dilated cardiomyopathy in identical twins. Am $\mathcal{F}$ Cardiol 1994;128:839-41. 


\title{
Hepatitis $G$ virus infection as a possible causative agent of community-acquired hepatitis and associated aplastic anaemia
}

\author{
J Crespo, B de las Heras, M Rivero, J L Lozano, E Fábrega, F Pons-Romero
}

Gastroenterology and Hepatology Unit, Faculty of Medicine, University Hospital 'Marqués de

Valdecilla', Santander, Spain

J Crespo

B de las Heras

M Rivero

J L Lozano

E Fábrega

F Pons-Romero

Correspondence to Dr Javier Crespo, Servicio Aparato Digestivo, Hospital

Universitario 'Marqués de

Valdecilla', Av Valdecilla s/n

Santander, E-39008

Cantabria, Spain

Accepted 2 September 1998

Table 1 The haematological, biochemical, serological, and virological course of the community-acquired hepatitis and associated aplastic anaemia

\begin{tabular}{|c|c|c|c|c|c|}
\hline Variable & fuly 1992 & Sep 1992 & Aug 1993 & Fuly 1994 & Dec 1994 \\
\hline Hemoglobin $(\mathrm{g} / \mathrm{l})$ & 151 & 145 & 100 & 135 & 137 \\
\hline White cells $\left(\times 10^{9} / 1\right)$ & 6.1 & 7.35 & 1.3 & 5.45 & 6.7 \\
\hline Platelets $\left(\times 10^{9} / 1\right)$ & 310 & 254 & 10 & 221 & 236 \\
\hline a PI $(\%)$ & 100 & 100 & 80 & 100 & 100 \\
\hline bAST (IU/1) & 941 & 40 & 451 & 51 & 35 \\
\hline${ }^{\mathrm{c}} \mathrm{ALT}(\mathrm{IU} / \mathrm{l})$ & 1812 & 45 & 1344 & 70 & 38 \\
\hline${ }^{d} \mathrm{AP}(\mathrm{IU} / \mathrm{l})$ & 190 & 83 & 185 & 95 & 75 \\
\hline éGGT (IÚ/1) & 364 & 45 & 218 & 40 & 45 \\
\hline${ }^{\mathrm{f}} \mathrm{TB}(\mu \mathrm{mol} / \mathrm{l})$ & 51.3 & 22 & 55.3 & 27.2 & 31.2 \\
\hline${ }^{8} \mathrm{HGV}-\mathrm{RNA}$ & Positive & Positive & Positive & Negative & Negative \\
\hline
\end{tabular}

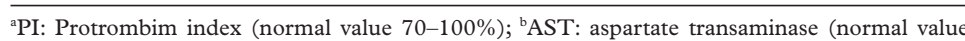
10-40 IU/1); ${ }^{\mathrm{c} A L T}$ : alanine transaminase (10-40 IU/1); ${ }^{\mathrm{d}} \mathrm{AP}$ : alkaline phosphatase $(40-120 \mathrm{IU} / \mathrm{l})$; ${ }^{\mathrm{e}} \mathrm{GGT}$ : gamma-glutamyltranspeptidase (10-50 IU/1); ${ }^{\mathrm{f}} \mathrm{TB}$ : total bilirubin $(3.42-17.1 \mu \mathrm{mol} / \mathrm{l})$; ${ }^{\mathrm{g}} \mathrm{HGV}-\mathrm{RNA}$ detected by polymerase chain reaction.

\begin{abstract}
Summary
Aplastic anaemia complicating hepatitis is a rare but well-documented phenomenon; however in many patients the cause remains unknown. We present a 24-yearold man with a well-defined communityacquired hepatitis, probably due to hepatitis G virus (HGV), who developed severe aplastic anaemia. In this case, the absence of other agents likely to cause the clinical manifestations, and the detection of HGV RNA at the time of illness, clearly point to this agent as being responsible for both the hepatitis and the aplastic anaemia. Further studies in serial serum samples and meticulous evaluation of the disorders associated with the infection will be needed to prove or dispute a causal association of HGV and aplastic anaemia.

Keywords: hepatitis G virus; aplastic anaemia

Aplastic anaemia complicating hepatitis is a rare but well-documented phenomenon. The mechanisms leading to marrow failure remain unclear. $^{12}$ The recent identification of the hepatitis $\mathrm{G}$ virus (HGV) has opened the field to the study of disease association with these new agents. ${ }^{34} \mathrm{HGV}-\mathrm{RNA}$ has been reported in sera from patients with acute, chronic, and fulminant hepatitis who lacked evidence of infection with known hepatitis viruses. ${ }^{3}{ }^{4}$ Of interest is an apparent link between $\mathrm{HGV}$ infection and cases of aplastic anaemia. ${ }^{56}$
\end{abstract}

Case report

On 10 July 1992, a previously healthy white 24-year-old heterosexual man presented with 5 weeks of malaise and 3 weeks of jaundice. The patient had had no exposure to industrial chemicals or to any proprietary or nonproprietary drugs. He denied use of any medications, intravenous drug abuse, blood transfusion, or alcohol ingestion. On examination, the patient was alert with minimal scleral icterus and without stigmata of chronic liver disease. Serologic markers for $\mathrm{HAV}, \mathrm{HBV}, \mathrm{HCV}, \mathrm{HEV}$, and HIV were repeatedly negative. HBV and $\mathrm{HCV}$ testing by polymerase chain reaction (PCR) did not detect HBV-DNA or HCVRNA. Virological and microbiological tests, including cytomegalovirus, Parbovirus B-19 (IgG and $\operatorname{IgM}$ ), toxoplasma, Epstein-Barr virus, herpes simplex virus, coxiella, and leptospira, were all negative. Antinuclear antibodies, anti-smooth muscle antibody, antimitochondrial antibody, and screen for Wilson's disease and haemochromatosis were also negative. Chest X-ray and ultrasound examination of the abdomen were normal. His clinical state improved over the next 10 weeks; liver function tests returned to normal levels by week 12 . On 5 August 1993 he was admitted to our hospital for evaluation of nose and gum bleeding and multiple haematomata. Examination revealed purpura of his oral mucosa and multiple petechiae. Virological and microbiological tests were again negative. Bone marrow biopsy showed a severely hypoplastic marrow and this, together with his low platelet and white cell counts, satisfied the criteria for severe aplastic anaemia. Over the following 2 weeks, he became progressively more pancytopenic and his aspartate transaminase and alanine transaminase returned to near normal ranges. On 25 August 1993 he received an allogenic bone marrow transplant. He has remained well for more than 2 years after transplantation. The laboratory results are summarised in table 1 .

HCV-RNA was investigated by PCR amplification of the $5^{\prime} \mathrm{NCR}$ as described previously. ${ }^{7}$ No cross-reactivity with HGV-RNA was found. HGV-RNA was investigated by PCR amplification of the 5' NCR as described previously. ${ }^{8}$ Briefly, nucleic acids were extracted from $100 \mu$ of serum using extraction columns (Quiagen, Hilden, Germany). RNA was transcribed into cDNA with M-MLV retrotranscriptase. The primers were NCR1: 
5'-CGGCCAAAAGGTGGTGGATG-3' and NCR2: 5'-CGACGAGCCTGACGTC GGG3'. Amplified cDNA sequences were detected by agarose gel electrophoresis with ethidium bromide staining. The specificity of the amplified bands was confirmed by an electroimmunoassay procedure (PCR ELISA (Dig detection, Boehringer Mannheim, Germany). Sera obtained before any blood products were given and throughout the clinical course, were positive for HGV. Similarly, serum obtained on presentation with aplastic anaemia was positive for HGV. Unfortunately, fresh bone marrow aspirates were not available to show whether HGV RNA was present in bone marrow. Sera obtained in July and December 1994, were negative for $\mathrm{HGV}$.

\section{Discussion}

Hepatitis-associated aplastic anaemia (HAAA) is a severe disorder with a high mortality; the responsible agent for most cases of HAAA has not been identified, although it is presumed to be viral. HGV has been postulated as the aetiologic agent of acute hepatitis, chronic liver disease of unknown aetiology, fulminant hepatitis, and HAAA. ${ }^{34}$ In our patient, we were able to detect HGV-RNA in the serum repeatedly before any blood transfusion. In this case, the $\mathrm{HGV}$ infection was demonstrated coincident with the two flares of hepatic necrosis, and for this reason a causative association can be inferred. The role of $\mathrm{HGV}$ in non-A-E community-acquired hepatitis is under investigation. ${ }^{9-11}$ Published case series have claimed an association between $\mathrm{HGV}$ and acute liver diseases, but case-control studies are required to confirm whether or not $\mathrm{HGV}$ is an aetiologic agent of viral hepatitis. ${ }^{9}$ The negative HGV RNA by PCR in the post-bone marrow transplant serum suggests HGV clearance in this patient. Few reports have analysed the role of $\mathrm{HGV}$ in the development of HAAA (table 2); however, the high prevalence of $\mathrm{HGV}$ in these cases may arise from disease treatment rather than from $\mathrm{HGV}$ being a causative agent of aplastic anaemia.

1 Brown KE, Tisdale J, Barrett J, Dunbar CE, Young NS. Hepatitis-associated aplastic anemia. $N$ Engl $\mathcal{f} \mathrm{Med}$ 1997;336:1059-64.

2 Kojima S, Matsuyama K, Kodera Y, Okada J. Circulating activated suppresor $\mathrm{T}$ lymphocytes in hepatitis-associated aplastic anemia. Br 7 Haematol 1989;71:147-51.

3 Simons JN, Leary TP, Dawson GJ, et al. Isolation of novel virus-like sequences associated with human hepatitis. Nat Med 1995;1:564-9.

4 Linnen J, Wages J Jr, Zhang-Keck ZY, et al. Molecular cloning and disease association of hepatitis $G$ virus: a transfusion-transmissible agent. Science 1996;271:505-8.

5 Zaidi Y, Chapman CS, Myint S. Aplastic anaemia after HGV infection. Lancet 1996;348:471-2.

6 Byrnes JJ, Banks AT, Piatack M, Kim JP. Hepatitis G-associated aplastic anaemia. Lancet 1996;348:472.
Table 2 Cases reported of possible HGV infection as a causative agent of hepatitis-associated aplastic anaemia

\begin{tabular}{lcl}
\hline Reference & npatients & HGV-RNA positive (\%) \\
\hline 1 & 10 & $3(30)$ \\
3 & 1 & $1(100)$ \\
5 & 1 & $1(100)$ \\
6 & 1 & $1(100)$ \\
10 & 4 & $4(100)$ \\
present case & 1 & $1(100)$ \\
\hline
\end{tabular}

The patient with HGV hepatitis we report here followed a pattern noted to be typical of HAAA. Moreover, after the bone marrow transplant, there was no further evidence of chronic hepatitis or HGV infection. Although the detection of HGV RNA at the time of illness, in the absence of other agents likely to cause the clinical manifestations, clearly points to this agent as being responsible for both the hepatitis and the aplastic anaemia, controversial issues should be addressed. First, the clinical significance of $\mathrm{HGV}$ remains uncertain..$^{8-10}$ Second, neither a specific location nor replication in the liver has yet been verified and HGV RNA has not been documented in fresh marrow aspirates. Third, we cannot exclude that our patient with $\mathrm{HGV}$ infection may have simultaneously acquired another unidentified agent(s) which might have caused the rise in liver enzymes and/or the aplastic anaemia. Fourth, several features of the HAAA suggest that it is mediated by immunopathologic mechanisms; for this reason, the causative agent of this syndrome may not be an infectious agent. ${ }^{1-2}$

In summary, in this case the absence of other agents likely to cause the clinical manifestations, and the detection of HGV RNA at the time of illness, clearly point to this agent as being responsible for both the hepatitis and the aplastic anaemia.

This work was supported by a grant from the Fondo de Investigaciones Sanitarias de las Seguridad Social, Spain (FISSss $94 / 1411$ ) and by a grant from the Fundación Marqués de Valdecilla, Santander, Spain

7 Crespo J, Carte B, Lozano JL, et al. Hepatitis C virus (HCV) recurrence after liver transplantation: Relationship to
anti-HCV core IgM, genotype, and level of viremia. $A m \mathcal{F}$ anti-HCV core IgM, genotype,
Gastroenterol 1997;92:1458-62.

8 Leary TP, Muerhoff AS, Simons JN, et al. Consensus oligonucleotide primers for the detection of GB virus C in human cryptogenic hepatitis. F Virol Meth 1996;56:119-21. 9 Alter MJ, Gallagher M, Morris TT, et al. Acute Non-A-E hepatitis in the United States and the role of hepatitis G virus infection. N Engl f Med 1997;336:741-6.

10 Kao J-H, Chen P-J, Hsiang S-C, et al. Phylogenetic analysis of GB virus C: comparison of isolates from Africa, North America and Taiwan. F Infect Dis 1996;174:410-3.

11 Alter HJ, Nakatsuji Y, Melpolder J, et al. The incidence of transfusion-associated hepatitis $G$ virus infection and its relation to liver disease. $N$ Engl f Med 1997;336:747-54. 


\title{
Primary antibody deficiency and Crohn's disease
}

\author{
P Conlong, Wynne Rees, J L Shaffer, David Nicholson, Derek Jewell, Mansel Heaney, \\ Aled Jones, Neil Snowden
}

Hope Hospital, Stott Lane, Salford M6 8HD, UK

P Conlong

W Rees

J L Shaffer

D Nicholson

D Jewell

M Heaney

A Jones

N Snowden

Correspondence to Dr P Conlong, 14 Lidgate Grove, Didsbury,

Manchester M20 6ST, UK

Accepted 2 September 1998

\begin{abstract}
Summary
Five patients with primary antibody deficiency were investigated because of intermittent but persistent diarrhoea of several years duration despite immunoglobulin replacement therapy. We found no evidence of Giardia lambia or other intestinal pathogens to explain their gastrointestinal symptoms. All five had definite radiological evidence of small bowel Crohn's disease and three had histological specimens available with abnormalities consistent with Crohn's disease. One patient had a non-caseating granuloma in an oral ulcer. A second patient with stricturing disease in the small bowel had a mucosal inflammatory infiltrate with non-caseating granulomas. A third had transmural inflammation but no granulomas. All five patents were diagnosed as having Crohn's disease and have responded symptomatically to steroid therapy.
\end{abstract}

Keywords: antibody deficiency; Crohn's disease

Some patients with primary antibody deficiency have an enteropathy. Infection is common and although immunoglobulin replacement therapy seems to have reduced the incidence of some bowel pathogens such as Giardia, Salmonella and Campylobacter, 10\% have diarrhoea, abdominal pain or weight loss which defies explanation. ${ }^{1}$

There is a broad spectrum of histological abnormality in these patients. In the stomach there is a high frequency of gastric atrophy and a predisposition to gastric carcinoma, ${ }^{2-4}$ whilst in the small bowel, lymphoid nodular hyperplasia is common. ${ }^{2}{ }^{3}$ In those with common variable immunodeficiency, there are well-documented cases of jejunal villous atrophy which may or may not respond to glu-

with Crohn's disease but the histology was apparently distinctive with the presence of microscopic colitis, increased intra-epithelial lymphocytes and an intact crypt architecture in the colon. Any inflammation in the small bowel was not transmural and there were no granulomas.

We investigated the cause of diarrhoea in five patients with primary antibody deficiency who were referred with refractory diarrhoea.

\section{Methods}

We investigated five patients who were referred with intermittent but persistent diarrhoea of several years duration from a cohort of 100 patients with primary antibody deficiency from the Department of Immunology at Hope Hospital in Manchester over a period of 8 years. There were four men (19-65 years) and one woman (54 years). One had X-linked agammaglobulinaemia (Bruton's disease), the others had common variable immunodeficiency. All five patients had been shown to have a primary immunological deficiency by their repeated failure to generate responses to common antigens such as pneumococcus, tetanus and pokeweed nitrogen. All were on regular immunoglobulin replacement therapy with Sandoglobulin (Sandoz Pharmaceuticals) at a dose of $0.3-0.4 \mathrm{~g} / \mathrm{kg} / \mathrm{month}$ with regular assessment of their immunoglobulin trough levels.

Two sets of three fresh stool specimens from each patient were examined for evidence of parasitic involvement or other pathogens. Each patient had a gastroscopy with duodenal biopsy, full colonoscopy and a small bowel enema. The specimens obtained were examined histologically for parasites.

Patients were commenced on steroid therapy and their response assessed according to improvements in their symptoms. They were then followed up over a 5-year period.

withdrawal; however, the diagnosis of coeliac disease has only been reliably proved in one patient after gluten withdrawal and challenge. ${ }^{6}$

There have been several case reports showing radiological appearances compatible with Crohn's disease in patients who have presented with diarrhoea and intestinal strictures, although the histology has generally not shown granulomas or transmural inflammation. ${ }^{7-11}$ Teahon and Webster, ${ }^{11}$ in their series of patients with primary antibody deficiency, proposed the existence of an enteropathy distinct from Crohn's disease. The radiology was consistent

\section{Results}

The main findings are shown the table. No pathogens were identified from several stool examinations specifically looking for Salmonella, Shigella, Campylobacter, ova and cysts. All of the patients had radiological evidence of small bowel abnormalities compatible with Crohn's disease. Patient 1 had nodular thickening throughout the jejunum and ileum (figures 1 and 2). Patient 2 showed stricturing disease in the duodenum and small bowel (figure 3 ). Patient 3 had a stenotic lesion in the terminal 
Table 1

\begin{tabular}{|c|c|c|c|c|c|c|c|c|}
\hline \multicolumn{2}{|c|}{ Patient } & \multirow{2}{*}{$\begin{array}{l}\text { Age } \\
19 \\
\text { mia }\end{array}$} & \multirow{2}{*}{$\begin{array}{l}\text { Sex } \\
M\end{array}$} & \multirow{2}{*}{$\begin{array}{l}\text { Presentation } \\
\text { Weight loss, loss } \\
\text { of appetite, } \\
\text { abdominal pain }\end{array}$} & \multirow{2}{*}{$\begin{array}{l}\text { Radiological abnormalities } \\
\text { Jejunum, ileum = nodular } \\
\text { thickening }\end{array}$} & \multirow{2}{*}{$\begin{array}{l}\text { Histological abnormalities } \\
\text { Mouth-granulomas, } \\
\text { non-caseating } \\
\text { S - not done } \\
\text { D - duodenitis, no atrophy } \\
\text { SB - none available } \\
\text { C - normal }\end{array}$} & \multirow{2}{*}{$\begin{array}{l}\text { Other features } \\
\text { Has developed a protein } \\
\text { losing enteropathy }\end{array}$} & \multirow{2}{*}{$\begin{array}{l}\begin{array}{l}\text { Other sites of } \\
\text { infection }\end{array} \\
\text { Bronchiectasis }\end{array}$} \\
\hline 1 & $\begin{array}{l}\mathrm{X} \text {-linked } \\
\text { agammaglobulinaen }\end{array}$ & & & & & & & \\
\hline 2 & CVID & 60 & M & $\begin{array}{l}\text { Oral ulcers, } \\
\text { abdominal pains, } \\
\text { weight loss }\end{array}$ & $\begin{array}{l}\text { Duodenum, jejunum, illeum } \\
=\text { stricturing } 2 \text { nd } \& 4 \text { th } \\
\text { parts of the duodenum \& } \\
\text { mid small bowel }\end{array}$ & $\begin{array}{l}\text { S - not done } \\
\text { D - not done } \\
\text { SB - granulomas, } \\
\text { inflammatory infiltrate, not } \\
\text { transmural } \\
\text { C - not done }\end{array}$ & $\begin{array}{l}\text { Stricturing disease in mid } \\
\text { small bowel requiring } \\
\text { resection }\end{array}$ & Nil \\
\hline 3 & CVID & 36 & M & $\begin{array}{l}\text { Diarrhoea, } \\
\text { abdominal pain }\end{array}$ & $\begin{array}{l}\text { Terminal ileum = skip } \\
\text { lesions \& ulceration with } \\
\text { stenotic lesions }\end{array}$ & $\begin{array}{l}\text { S - normal } \\
\text { D - total villous atrophy, crypt } \\
\text { hyperplasia, intraepithelial } \\
\text { lymphocytes } \\
\text { SB - none available } \\
\text { C = non-specific } \\
\text { inflammation }\end{array}$ & $\begin{array}{l}\text { Has developed } \\
\text { spondyloarthopathy } \\
\text { affecting large joints }\end{array}$ & $\begin{array}{l}\text { One episode } \\
\text { of meningitis }\end{array}$ \\
\hline 4 & CVID & 33 & M & $\begin{array}{l}\text { Diarrhoea, right } \\
\text { iliac fossa pain }\end{array}$ & $\begin{array}{l}\text { Terminal ileum }= \\
\text { oedematous, with rose thorn } \\
\text { ulcerations }\end{array}$ & $\begin{array}{l}\text { S - normal } \\
\text { D - normal } \\
\text { SB - none available } \\
\text { C - non-specific inflammation }\end{array}$ & & Bronchiectasis \\
\hline 5 & CVID & 52 & $\mathrm{~F}$ & $\begin{array}{l}\text { Bloating, } \\
\text { diarrhoea, } \\
\text { abdominal pain }\end{array}$ & $\begin{array}{l}\text { Terminal ileum }=\text { ulceration } \\
\text { and stricturing disease }\end{array}$ & $\begin{array}{l}\text { S - gastritis, no atrophy } \\
\text { D - not done } \\
\text { SB - mild transmural } \\
\text { inflammation, patchy } \\
\text { inflammatory cells, no } \\
\text { granulomas } \\
\text { C - normal }\end{array}$ & $\begin{array}{l}\text { Required terminal ileum } \\
\text { resection }\end{array}$ & $\begin{array}{l}\text { Recurrent } \\
\text { chest infection }\end{array}$ \\
\hline
\end{tabular}

CVID = common variable immunodeficiency, $\mathrm{S}=$ stomach, $\mathrm{D}=$ duodenum, $\mathrm{SB}=$ small bowel, $\mathrm{C}=$ colon.

ileum with skip lesions and ulceration. Patient 4 had rosethorn ulceration of the terminal ileum. Patient 5 also had stricturing disease in the terminal ileum (figure 4).

There was a wide spectrum of histological abnormality. Patient 1 had granulomatous ulceration in the mouth and duodenitis. Patient 3 had total villous atrophy on duodenal biopsy with increased intra-epithelial lymphocytes and crypt hyperplasia. Patient 5 had gastritis. Patients 2 and 5 needed resections for obstructive symptoms. One resected terminal ileal

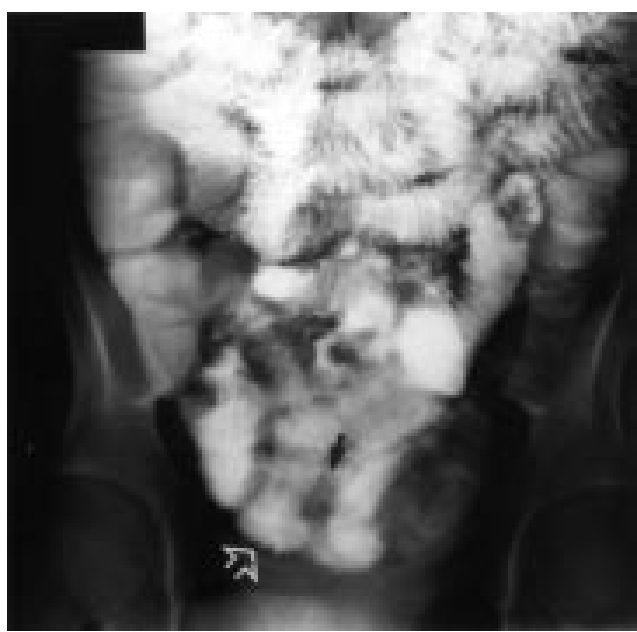

Figure 1 Film on barium follow-through study (patient 1). There is mild thickening and nodularity of the jejunum. In addition in this case more diseased loops of bowel are seen within the pelvis where the nodularity is more marked (open white arrow) and there is associated luminal narrowing with bowel loop separation (black arrow) specimen revealed an inflammatory nontransmural lymphocytic infiltrate, fibrosis and two non-caseating granulomas. The other resected ileal specimen showed transmural lymphocytic inflammation without granulomas. In the colon of patients 3 and 4 the specimens demonstrated a mild non-specific inflammation restricted to the mucosa which was mainly lymphocytic with some neutrophils, infiltration, no crypt abscesses, and without

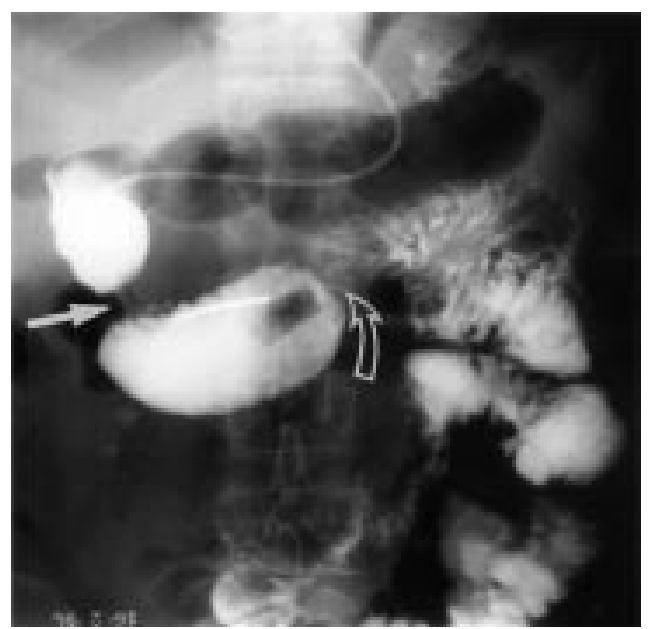

Figure 2 Film from small bowel enema (patient 2). Note the small bowel enema tip in third part of duodenum. Strictures are evident: the first (white arrow) is at the junction of the second and third part of the duodenum. A second stricture is seen in the region of the DJ flexure (curved open arrow). This is causing pre-stenotic dilatation of the third part of the duodenum which contains a filling defect/food residue. Contrast has, however, passed beyond this point into the proximal jejunum 


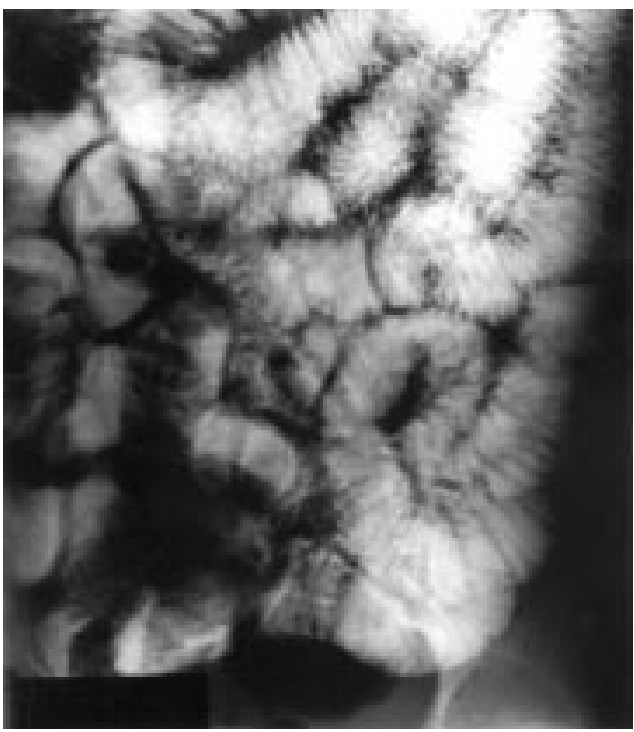

Figure 3 Film from small bowel follow-through series (patient 2). There is mild, diffuse nodular thickening of the jejunum and proximal ileum. No structuring disease is identified. The appearances are non-specific but can be seen in diffuse Crohn's jejunal ileitis as well as many other conditions such as Giardiasis.

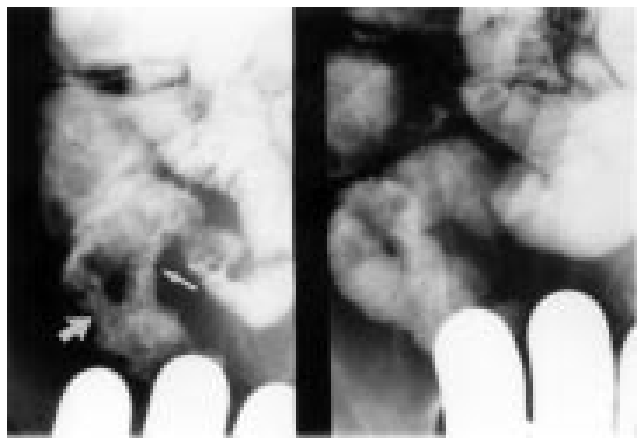

Figure 4 Cone view of right iliac fossa during small bowel enema (patient 5). The distal terminal ileum shows stricturing in several places (white arrows). The folds are thickened and there is nodularity with several adverse ulcers. These are most prominent between the two labelled strictures.

intra-epithelial lymphocytes. There was no evidence of parasites in any of the specimens examined.

Patients 1 and 3 who had particularly severe symptoms were treated with budesonide but did not respond and were controlled on regular prednisolone. The other three patients responded to short courses of prednisolone following commencement of steroids, a clinical improvement was documented by a significant reduction in stool frequency.

\section{Discussion}

The five patients described had Crohn's disease. We found no evidence to support the existence of a separate enteropathy associated with primary antibody deficiency. One might have expected that infection would explain these patients relapsing and remitting gastrointestinal symptoms. After all, the majority had evidence of infection in other body systems, but despite looking for pathogens in stools and histological specimens none was ever implicated. It could be argued that we did not look aggressively enough for micro-organisms. $\mathrm{Mi}$ crosporidia and Cyclospora are difficult to detect on haematoxylin and eosin sections; electron micrographs would perhaps have been preferable. It is also difficult to attain a perfect plateau of immunoglobulin replacement, even with frequent monitoring of trough levels, and Sandoglobulin contains predominantly IgG with only small amounts of $\operatorname{IgA}$, the principal bowel immunoglobulin.

All of our patients had radiological evidence of small bowel involvement varying from stricturing disease requiring surgical resection in two patients to nodular thickening in the jejunum and ileum or rosethorn ulceration. The histological abnormalities were very diverse. Two patients had non-caseating granulomas; in one, this was present in a lesion in the mouth and the other in a resected terminal ileal specimen. This latter patient, however, had a predominantly mucosal rather than transmural lymphocytic infiltrate. The other patient who needed a terminal ileal resection for stricturing disease had a mild transmural lymphocytic infiltrate without granulomas.

Total villous atrophy with increased intraepithelial lymphocyte infiltration was found in one patient on duodenal biopsy but he showed no improvement in histological appearance with gluten withdrawal. Another had lymphocytic infiltration in the duodenum but no other abnormalities. In colonic specimens, two patients had mild inflammation restricted to the mucosa, with an intact crypt architecture and no increase in intra-epithelial lymphocytes.

We would argue that the pattern of histological and radiological findings demonstrate these patients to have Crohn's disease rather than belonging to a different grouping as originally proposed by Teahon and Webster. ${ }^{11}$

Patients 2 and 5 needed small bowel resections for stricturing disease in the early part of their clinical course; their subsequent gastrointestinal symptoms have responded well to short courses of prednisolone, as have those of patient 4. Two other patients (1 and 3) were tried on $9 \mathrm{mg}$ of budesonide but did not respond and have better disease control on regular prednisolone therapy, with one of these also tolerating and responding to an elemental diet. Patient 1 with $\mathrm{x}$-linked agammaglobulinaemia has recently developed a protein-losing enteropathy initially suggested by rising requirements for immunoglobulin therapy. Interestingly, this problem appears to have been controlled with steroid therapy.

The aetiology of Crohn's disease is still unknown. A variety of hypotheses exist but none have been proved. Immune function has been extensively tested in Crohn's patients. There have been studies suggesting mild defects in neutrophil functions, both in ability to phagocytose ${ }^{12}$ and in chemotaxis on 'skin 
windows $^{13}$ (serum-filled perspex windows placed over abraded skin). Others, however, have shown normal neutrophil oxidative ability $^{1415}$ and normal chemotaxis in vitro. All in all, these probably add up to mild defects in phagocyte function. Lymphocyte function is thought to be normal in Crohn's disease; although there is a specific increase in IgG2

1 Webster ADB. Immune deficiency syndrome and the gut. In: Peters TJ, ed, The cell biology of inflammation in the gastro; pp 231-48

2 Ament ME. Immunodeficiency symptoms and the gut. Scand $\mathcal{F}$ Gastroenterol 1985;20:127-35.

3 Hermans PE, Diaz-Buxo JA, Stobo JD. Idiopathic late onset immunoglobin deficiency. Clinical observations in 50 patients. Am ₹ Med 1976;61:221-37.

4 Hermans PE, Huizenga KA. Association of gastric cancer with idiopathic late immunoglobin deficiency. Ann Intern Med 1972;76:605-9.

5 Hermans PE, Huizenga KA, Hoffman HN, Brown AL, Marcowitz H. Dysgamaglobinaemia associated with nodular lymphoid hyperplasia of small intestine. Am f Med 1966; 40:78-89.

6 Webster ADB, Slavin G, Shiner M, Platts-Mills TAE Asherson GL. Coeliac disease with severe hypogamaglobinaemia. Gut 1981;22:153-7.

7 Soltoft J, Petersen L, Kruse P. Immunoglobin deficiency and regional enteritis. Scand F Gastroenterol 1972;7:233-6.

8 Strauss RG, Chisan F, Mitros F, et al. Rectosigmoid colitis in common variable immunodeficiency. Dig Dis Sci 1980;25:798-801.

9 Fillit H, Bernstein L, Davidson M, Brandt L, Bezahler G, Cohen M. Primary acquired hypogammaglobinaemia and regional enteritis. Arch Intern Med 1977;137:1252-4. immunocytes. ${ }^{16}$ It is not known how many patients with Crohn's have primary antibody deficiency.

In conclusion, we report five patients with primary antibody deficiency who also have Crohn's disease defined radiologically and histologically, and whose symptoms are controlled on steroid therapy.

10 Mir-Madjlessi SH, Tavassolie H, Kamalian N. Malakoplakia of the colon and recurrent colonic strictures in a patient with primary hypogammaglobinaemia. Dis Colon Rectum 1982; 25:723-7.

11 Teahon K, Webster AD, Price AB, Weston J, Bjarnason I. Studies on the enteropathy associated with primary hypogammglobulinaemia. Gut 1994;35:1244-9.

12 Nielsen OH, Elmgreen J, Thomson BS, Ahnfelt-Ronne I, Wilk A. Release of leukotrine B4 and 5 hydroxyeicosotetranoic acid during phagocytosis of artificial complexes by peripheral neutrophils in chronic inflammatory bowel disease. Clin Exp Immunol 1986;65:465-71.

13 Segal AW, Loewi G. Neutrophil dysfunction in Crohn's disease. Lancet 1976;2:219.

14 Koldkjaer O, Klitgaard NA, Schmidt KG. Cellular and humoral indices of disease activity in inflammatory bowel disease. Digestion 1978;17:387

15 Ward M, Eastwood MA. The nitroblue tetrazaluim test in Crohn's disease and ulcerative colitis. Digestion 1979;14:179.

16 Kett K, Rognum TO, Brandtzaeg P. Mucosal subclass distribution of IgG producing cells is different in ulcerative colitis and Crohn's disease of the colon. Gastroenterology 1987;93:919-24.

\title{
Brain parenchymal, subarachnoid racemose, and intraventricular cysticercosis in an Indian man
}

\author{
D Ghosh, T N Dubey, S Prabhakar
}

\begin{abstract}
Summary
The coexistence of brain parenchymal cysts at various stages of evolution, both intraventricular and subarachnoid racemose, is reported in a patient with neurocysticercosis. The condition has a variety of presentations, depending on the location of the cyst. This case is of particular interest because of the rarity of this condition in India.
\end{abstract}

Department of

Neurology,

Postgraduate Institute

of Medical Education

and Research,

Chandigarh 160 012,

India

D Ghosh

T N Dubey

S Prabhakar

Correspondence to

Dr D Ghosh, Department of

Pediatrics, Advanced

Pediatric Centre,

Postgraduate Institute of

Medical Education and

Research, Chandigarh 160

012 , India

Accepted 4 August 1998
Keywords: brain parenchymal cyst; cysticercosis; albendazole

Cysticercosis is caused by cysticercus larvae of Tenia solium. The most common manifestation of neurocysticercosis is seizure due to brain parenchymal cysts at various stages of evolution. ${ }^{1}$ Subarachnoid and intraventricular cysts are rarely seen in India. In Mexicans, however, they are more common (up to $10 \%$ of all cases). ${ }^{2}$ Subarachnoid cysts are of the racemose type, as are the majority of intraventricular ones. A combination of cysticercus cysts in these locations is rather uncommon, especially in the Asian subcontinent. Considering the varied presentations of neurocysticercosis, de- pending on the location of the cysts, it was felt to be worthwhile reporting this case. Some of the varied presentations and their pathogenesis are also discussed.

\section{Case report}

A 50-year-old man presented to the neurology out-patient department with history of leftsided sensorimotor seizures for the last 3 years with a frequency of once every one or two months. There was secondary generalisation at times. There was also a history of complex partial seizures for the last 6 months. These were characterised by episodic altered behaviour, aimless running around, and complete amnesia for the events. He had suffered from recurrent, nonthrobbing left parieto-occipital headaches, each lasting for a few hours, for the last 18 months. Accompanying the headache, he experienced tinnitus in both ears and vertigo, but there was no vomiting or visual symptoms. He gave a history of pork ingestion. He was on a maintenance of dose of phenytoin. He had received albendazole for a month in November 1994.

His general examination was normal. Systemic examination was unremarkable. The 
fundus did not show any papilloedema. There was no neurodeficit or meningeal signs. The haemogram was normal and biochemical parameters were within normal limits. Cerebrospinal fluid (CSF) analysis showed 55 cells (all lymphocytes) with protein $2 \mathrm{~g} / 1$, sugar 0.2 $\mathrm{g} / 1$ (corresponding blood sugar $1.1 \mathrm{~g} / \mathrm{l}$ ), Gram stain was negative and culture sterile. Cysticercus serology (IHA) in blood and CSF was 1:8 (not suggestive). Contrast-enhanced computed tomography (CT) scan of the head showed multiple active parenchymal cysts and an enlarged left sylvian fissure (figure 1). Magnetic resonance imaging (MRI) of the brain showed multiple hypointense lesions on $\mathrm{T}_{1}$ becoming hyperintense on $\mathrm{T}_{2}$ - weighted image, with multiple cysts in the left sylvian fissure with septations (figure $2 \mathrm{~A}$ and $\mathrm{B}$ ). No scolex was seen within the racemose cyst. There was an intraventricular cyst in the right posterior horn, seen more clearly on proton density imaging (figure 2C).

In summary, this patient had multiple cysts (cysticercus) in the brain parenchyma, intraventricular region, and a racemose cyst in the left sylvian fissure. In the absence of any acute neurological signs, it was decided to try medical therapy for one month and then re-evaluate the situation.

\section{Discussion}

The clinical manifestations of neurocysticercosis are determined by the load of organisms, location of cysts, whether the cyst is dead or alive, and the response of the host. ${ }^{1}$ Parenchymal neurocysticercosis occurs most commonly at grey-white matter junctions. Neurocysticercosis is a common cause of late-onset seizure in countries where it is prevalent. Focal seizures are most common, but generalised tonic-clonic seizures are also observed. While parenchymal neurocysticercosis presents with seizures, subarachnoid neurocysticercosis usually presents with meningitis and raised intracranial pressure. Cysticercosis of the basal cistern is severe and frequently fatal. This variant is caused by a racemose form of cysticercosis which may cause obstruction to 4 th ventricular outflow. ${ }^{3}$ Subarachnoid cysticercosis can cause specific neurologic syndromes when large lesions are located in the cerebellopontine angle, sylvian fissure, ${ }^{4}$ or the convexity. Intraventricular cysts are frequently found in association with subarachnoid cysts. The fourth ventricle is the most common site. ${ }^{5}$ They usually present as a syndrome of hydrocephalus and increased intracranial pressure. Free floating cysts in ventricles can cause Brun's syndrome, characterised by intermittent foramen obstruction causing episodic recurrent headaches, vertigo, ataxia and drop attacks.

The racemose form of neurocysticercosis is a collection of transient membranes forming a cluster like a bunch of grapes, ${ }^{6}$ thought to be a forme fruste of cysticercus cellulosae. ${ }^{7} \mathrm{Su}-$ pratentorial racemose cysts are usually found in the sulci. When vesicles break down, an intense inflammatory reaction may occur in the

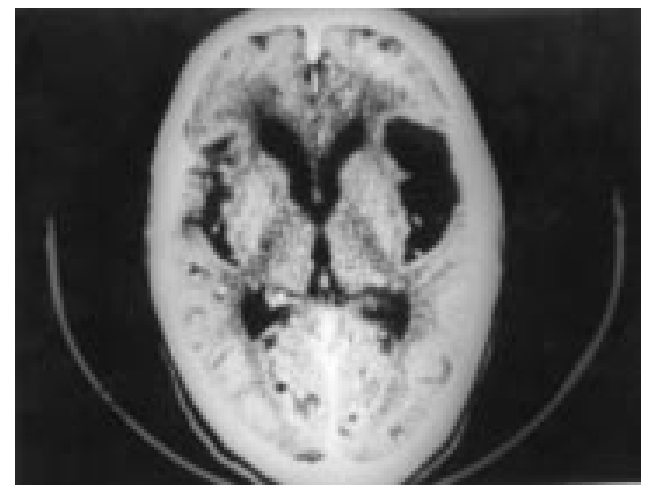

Figure 1 Contrast-enhanced CT scan of the head showing large CSF density lesion in the left sylvian fissure with incomplete septation. Multiple parenchymal cysts can be seen, some with visible scolices
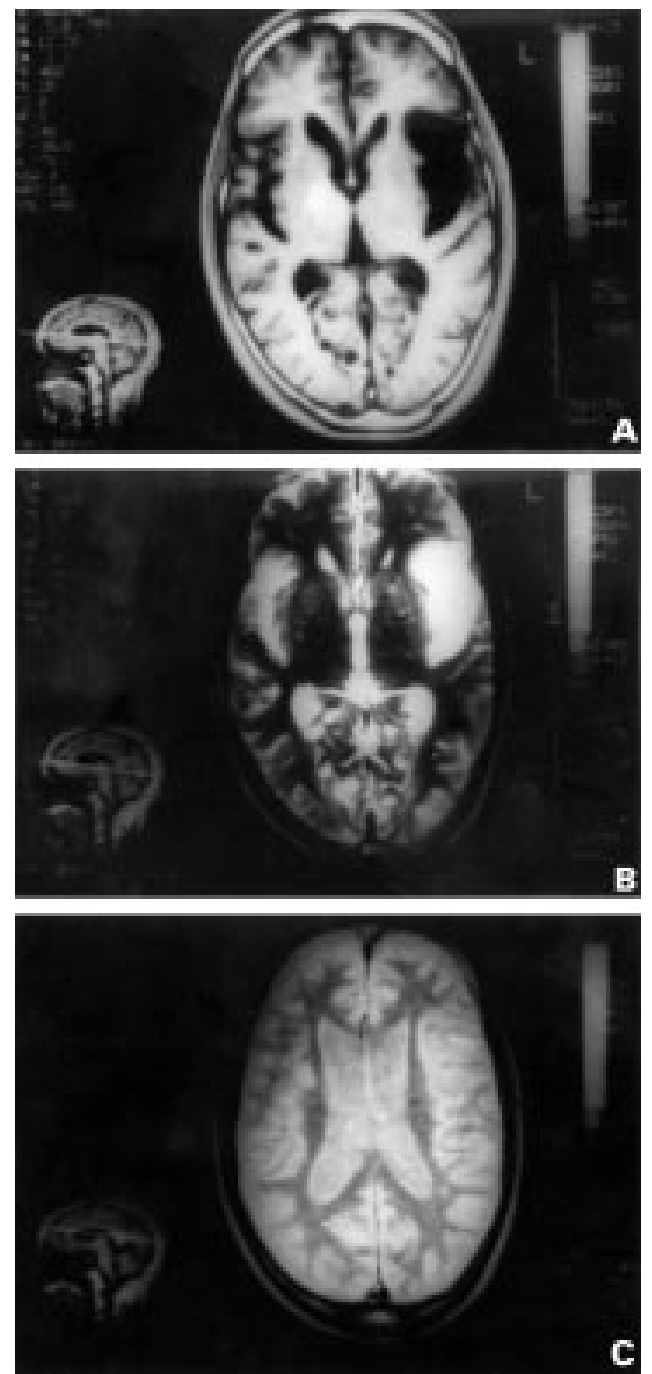

Figure 2 Brain MRI scans. (A) $\mathrm{T}_{1}$-weighted image, showing the left sylvian fissure containing multiple thin-walled large racemose cysts along with many parenchymal cysts. The lesions are hypointense; (B) $\mathrm{T}_{2}$-weighted image showing hyperintensity of the cyst fluid at the left sylvian fissure and multiple parenchymal cysts, some with perifocal oedema; (C) proton density MRI showing right posterior horn of lateral ventricle containing an intraventricular cyst 
subarachnoid space, causing arachnoiditis and hydrocephalus.

Cysticercus racemose was first described by Virchow in 1860. It is found in serious cases of cerebral cysticercosis and is characterised by larger size $(4-12 \mathrm{~cm})$, absence of scolex and a variable appearance. The coexistence of racemose and cellulosae is rare in Asian countries but not uncommon in Mexico (found in $10 \%$ of cases). ${ }^{2}$ The racemose type is more common in the suprasellar area, the cerebellopontine angle and sylvian fissure. The proliferating connective tissue encircles the characteristic bladder wall of the parasite.

Subarachnoid and intraventricular racemose cysts are more easily diagnosed by gross inspection than by microscopy, as they show typical budding of the vesicular wall. In intraventricular cysts there is more intense granulomatous inflammation. The ependymal lining is lost, with subependymal gliosis, ependymitis, and perivascular cuffing. ${ }^{8}$ As the cyst degenerates, granulomatous ependymitis and gliosis are the only residual histological findings.

According to some authors, cysticercus racemose may actually be due to a different variety of cestode, including Tenia solium, Tenia multiceps, and Tenia serialis. ${ }^{9}$ In few specimens degenerated scolices have been found, suggesting $T$ solium as the aetiological agent. ${ }^{11}$

CT scan in subarachnoid cysticercosis most commonly shows hydrocephalus, which may be communicating or non-communicating. ${ }^{12}$ There may be contrast enhancement of tentorium and basilar cistern secondary to arachnoiditis and fibrosis. The vessel involvement can lead to infarction. Intraventricular cysticercus is difficult to diagnose by CT scan alone. Obstructive hydrocephalus in the presence of a low-density intraventricular lesion may give a clue. The cysts enhance with contrast.

1 Del Bruto OH, Garcia E, Talamas O, Sotelo J. Sex related severity of inflammation in parenchymal brain cysticercosis. Arch Intern Med 1988;148:544-6.

2 Rabiela-Cerrantos MR, Rivas-Hernandez A, RodriguesIlbara J, Castillo Medina S, Cacino FM. Anatomical pathological aspects of human brain cysticercosis. New York: Academic Press, 1982; pp 179-99.

3 McCormick GF. Cysticercosis - review of 230 patients. Bull Clin Neurosci 1985;50:76-101.

4 Martinez-Lopez M, Ferrari FQY. Cysticercosis. 7 Clin Neurol Ophthalmol 1985;5:127-43.

5 Sotelo J, Guerrero V, Rubio F. Neurocysticercosis : a new Sotelo J, Guerrero V, Rubio F. Neurocysticercosis : a new
classification based on active and inactive forms. Arch Intern Med 1985;145:442-5.

6 Escobar A. The pathology of neurocysticercosis. In : Palacios E, Rodrigues-Carbajal J, Taveras JM, eds. Cysticercosis of the central nervous system. Springfield IL: Charles C Thomas, 1983; pp 27-54.

7 Gutierrez Y. Cysticercosis, coenurosis and sparganosis. In: Diagnostic pathology of parasitic infections with clinical correlations. Philadelphia: Lea and Febiger, 1990; pp 432-59.

8 Itabashi HH. Pathology of CNS cysticercosis. Bull Clin Neurosci 1983;48:6-17.
CT criteria to differentiate between cellulose and racemose cysts

- cellulose cysts are usually located intra-axially, ie, in brain tissue, while racemose cysts are frequently seen in basal cisterns, particularly the suprasellar area and cerebellopontine angle

- racemose cysts are usually bigger, appear as multiloculated cysts resembling 'bunches of grapes', elicit a more intense inflammatory reaction and frequently act as a space-occupying lesion

- in racemose varieties, no scolex is found

MRI is currently the most useful imaging tool for neurocysticercosis. Subarachnoid neurocysticercosis is better seen on MRI than on CT. Similarly, MRI is better for detection of cisternal cysts. ${ }^{13} \mathrm{~T}_{1}$-Weighted images are better for delineating cisternal wall while $\mathrm{T}_{2}$-weighted images are better in detecting oedema and arachnoiditis. Gadolinium-DTPA contrast in $T_{1}$ images enhances leptomeninges, suggesting inflammation. Racemose cysts have a similar signal intensity to that of CSF. ${ }^{14}$ Intraventricular neurocysticercosis must be suspected when hydrocephalus is present. MRI is superior to CT scan in detection of intraventricular cyst. ${ }^{14}$ Proton density images may better delineate the cyst from the CSF around the cyst, ${ }^{13}$ as shown in the present case.

Ventricular shunting is indicated for hydrocephalus. ${ }^{12}$ Cyst extirpation and drainage is indicated for racemose cysticercosis. Intraventricular neurocysticercosis also needs extirpation and/or surgical drainage. A few cases have been treated successfully by albendazole alone. ${ }^{15}$

Subarachnoid, intraventricular, spinal and mixed types of neurocysticercosis may behave in a malignant way with worse outcome. ${ }^{12}$

9 Jung RC, Rodrigues A, Beaver PC, Schenthal JE, Levy RW. Racemose cysticercus in human brain. A case report. $A m \mathcal{F}$ Trop Med Hyg 1981;30:620-4.

10 Escobar A. The pathology of neurocysticercosis. In: Palacios E, Rodrigues-Carbajal J, Taveras JM, eds. Cysticercosis of the central nervous system. Springfield IL: Charles C Thomas, 1983; pp 27-54.

11 Berman JD, Beaver PC, Cheever AW, Quindlen EA. Cysticercus of 60 milliter volume in human brain. $A m \mathcal{F}$ Trop Med Hyg 1981;30:616-9.

12 Sotelo J, Marin C. Hydrocephalus secondary to cysticercotic arachnoiditis. A long term follow up review of 92 cases. f Neurosurg 1987;66:686-9.

13 Zee CS, Segall HD, Boswell W, Ahmadi J, Nelson M, Colleti P. MRI imaging of neurocysticercosis. $\mathcal{F}$ Comput Assist Tomogr 1988;12:927-34.

14 Suss RA, Maravilla KR, Thompson J. MR imaging of intracranial cysticercosis: comparison with CT and anatomopathologic features. AFNR 1986;7:235-42.

15 Del Bruto OH, Sotelo J. Albendazole therapy for subarachnoid and ventricular cysticercosis. Case report. $\mathcal{F}$ Neurosurg 1990;72:816-7. 


\title{
Internal iliac artery embolisation for intractable bladder haemorrhage in the peri-operative phase
}

\author{
Sandeep Gujral, Richard Bell, Julian Kabala, Rajendra Persad
}

\begin{abstract}
Summary
Intractable haemorrhage from the bladder wall during transurethral resection of bladder tumour is uncommon but potentially catastrophic. Internal iliac artery embolisation is a minimally invasive technique, which is now widely practised to stop bleeding from branches of these arteries in situations including pelvic malignancy, obstetric and gynaecological emergencies and trauma. We report its successful use peri-operatively, in an unfit, elderly patient with uncontrolled bleeding.
\end{abstract}

Keywords: embolisation; internal iliac artery; transurethral resection of bladder tumour

Severe haemorrhage from the bladder wall during and following transurethral resection of bladder tumour (TURBT) can be life threatening. Methods of management for uncontrolled bladder bleeding include cystoscopic clot evacuation with cystodiathermy, Helmstein balloon compression, ${ }^{1}$ irrigation with alum solution, ${ }^{2}$ and instillation of formalin, ${ }^{3}$ and may finally culminate in open surgical techniques ranging from simple packing of the bladder to cystectomy and urinary diversion. ${ }^{4}$ Most patients in this situation are elderly and unfit and therefore unlikely to withstand these latter morbid procedures, especially as they require regional or general anaesthesia. Prolonged hypovolaemia and the associated massive blood transfusions that may be required are also poorly tolerated.

Internal iliac artery embolisation has been successfully used in controlling bladder haemorrhage from terminal pelvic malignancy for over 20 years. ${ }^{56}$ This case report illustrates its added value in the transurethral peri-operative phase.

\section{Case report}

Bristol Royal Infirmary, Bristol BS2 8HW, UK

Department of Urology

S Gujral

R Bell

R Persad

Department of

Radiology

J Kabala

Accepted 2 September 1998 recurrence predominantly on the left side and occupying over $70 \%$ of the bladder surface
A frail 79-year-old man with superficial, high-grade transitional cell carcinoma of the for 3 years, was admitted for transurethra resection under general anaesthesia of recurrent bladder tumour. There was no history of recent haematuria and his haemoglobin level was $10.2 \mathrm{~g} / \mathrm{dl}$. Clotting profile was normal.

Cystoscopy revealed an extensive tumour area. Resection of the tumour was difficult due to excessive bleeding. After 25 minutes, he became cardiovascularly unstable and was transfused with two units of blood. It was not

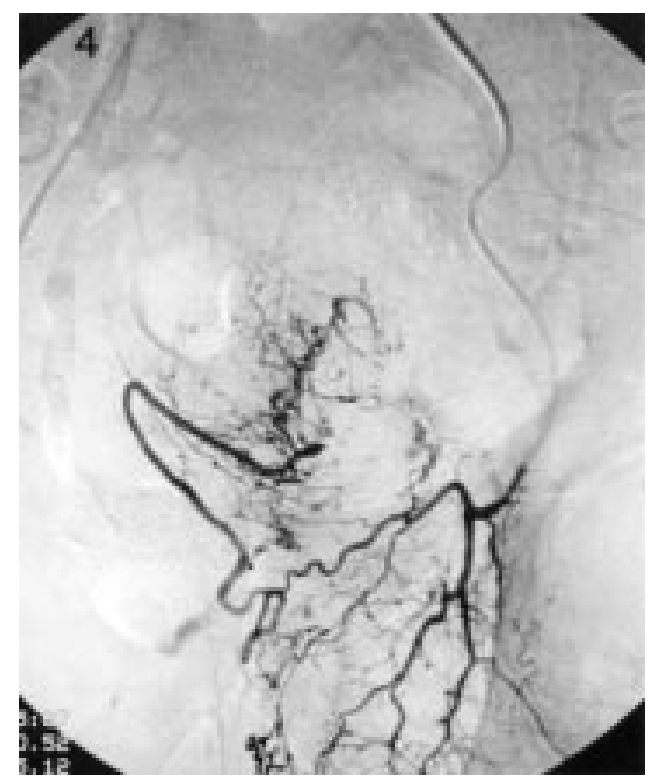

Figure 1 Pre-embolisation subtraction arteriogram showing selective contralateral catheterisation of the left internal iliac artery with significant vascular supply to the bladder wall tumour

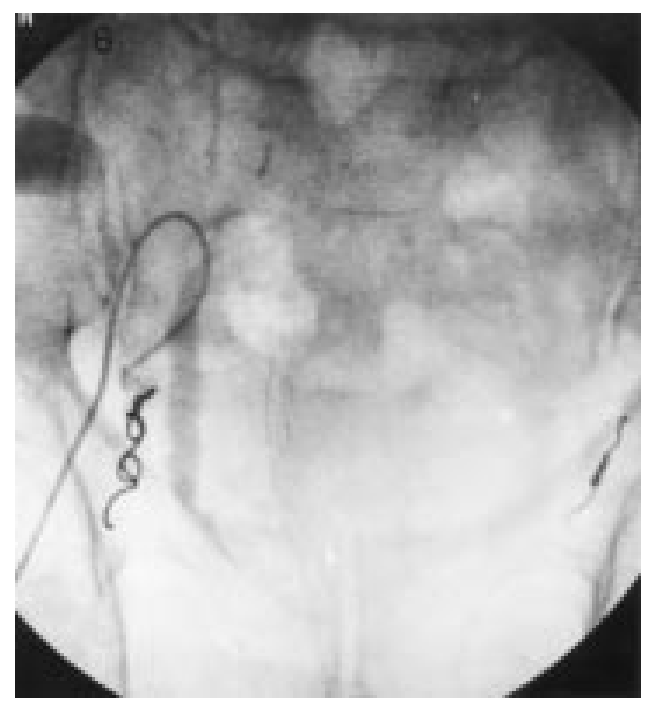

Figure 2 Post-embolisation subtraction arteriogram showing occlusion coils bilaterally within the anterior divisions of the internal iliac arteries 
possible to control the bleeding endoscopically and he was deemed too unfit to undergo an open surgical procedure. Immediate transfer to the radiology suite was organised for bilateral internal iliac artery embolisation. A pelvic arteriogram was performed and the anterior division of the contralateral internal iliac artery supplying branches to the left bladder wall, was identified. This illustrated the significant vasculature supplying the tumour in the left bladder wall (figure 1). Embolisation of the anterior division of the left internal iliac artery was carried out using occlusion coils and repeated on the right side to prevent any collateral circulation (figure 2). Immediate control of the haemorrhage was achieved without complications. His haemoglobin level was $9.7 \mathrm{~g} / \mathrm{dl}$ following two further units of blood and he made a full recovery. $\mathrm{He}$ declined any further surgical intervention, but was well at 3 months with no further haematuria.

\section{Discussion}

Internal iliac artery embolisation for the palliation of severe bladder haemorrhage in inoperable malignancy results in good initial control in $80-100 \%$ of patients. The duration of control is usually life long in these terminal cases. ${ }^{7}$ Complications arising from the procedure are uncommon and include sepsis, gluteal pain, gait disturbances and, very rarely, bladder necrosis. $^{8}$

1 Holstein P, Jacobsen K, Pedersen JF, Sorensen JS. Intravesical hydrostatic pressure treatment: new method for control of bleeding from the bladder mucosa. $\mathcal{F}$ Urol 1973;109:2346.

2 Kennedy C, Snell ME, Witherow RO. Use of alum to control intractable vesical haemorrhage. Br f Urol 1984;56:673-

3 Shrom SH, Donaldson MH, Duckett JW, Wein AJ. Formalin treatment for intractable haemorrhagic cystitis. A review of the literature with 16 additional cases. Cancer $1976: 38$. 1785-9.

4 Pomer S, Karcher G, Simon W. Cutaneous ureterostomy as last resort treatment of intractable haemorrhagic cystitis following radiation. Br f Urol 1983;55:392-4.

5 Hald T, Mygind T. Control of life threatening vesical haemorrhage by unilateral hypogastric artery muscle embolisaorrhage by unilateral hypogas
tion. $\mathcal{F}$ Urol 1974;112:60-3.

\section{Summary points}

- severe bladder haemorrhage from surgery or pelvic malignancy per se, can be difficult to control and is life threatening

- internal iliac artery embolisation is a minimally invasive technique which successfully stems intractable haemorrhage in the majority of cases

- early referral of suitable patients to the radiologist reduces morbidity related to prolonged hypovolaemia and associated blood transfusions and negates the need for more radical open surgical procedures

This case report illustrates the value of the procedure in the acute transurethral perioperative phase, when haemostasis is proving to be difficult to achieve. Previous reports ${ }^{9}$ have shown the efficacy of embolisation in the early postoperative period but this was undertaken only after massive blood transfusions had been given for prolonged hypovolaemia, with the attendant risks including consumptive coagulopathy, multi-organ failure, transfusion reactions, and possible blood-borne infections. This case demonstrates that providing there is good liaison between urologist and radiologist, early peri-operative referral of an unfit patient for arterial embolisation results in minimal total blood loss and therefore avoids the morbidity of multiple blood transfusions. It also avoids the use of more invasive techniques to achieve haemostasis.

6 Kobayashi T, Kusano S, Matsubayashi T, Uchida T. Selective embolisation of the vesical artery in the management of massive bladder haemorrhage. Radiology 1980;136:345-8.

7 Jenkins CNJ, McIvor J. Survival after embolisation of the internal iliac arteries in ten patients with severe haematuria due to recurrent pelvic carcinoma. Clin Radiol 1996;51:8658.

8 Wells I. Internal iliac artery embolisation in the management of pelvic bleeding (Editorial). Clin Radiol 1996;51: $825-7$.

9 Appleton DS, Sibley GNA, Doyle PT. Internal iliac artery embolisation for the control of severe bladder and prostate haemorrhage. Br f Urol 1988;61:45-7. 


\title{
Good prognosis in thyroid cancer found incidentally at surgery for thyrotoxicosis
}

\author{
Louiza Vini, Stephen Hyer, Brenda Pratt, Clive Harmer
}

\begin{abstract}
Summary
An analysis of the outcome of thyroid carcinoma incidentally discovered in patients undergoing surgery for hyperthyroidism is presented. Among 986 patients with differentiated thyroid cancer, 23 had presented with symptoms and signs of hyperthyroidism. Graves' disease was diagnosed in 11, multinodular goitre in eight and toxic adenoma in four. Following thyroidectomy, histology revealed papillary (18), follicular (four) and Hurthle cell (one) carcinoma. Tumour size ranged from $4 \mathrm{~mm}$ to $5.5 \mathrm{~cm}$, multifocality was detected in three patients, and lymph node involvement in one. Two patients (one with associated Graves' disease, one with multinodular goitre) relapsed locally and required further surgery; one developed distant metastases and died 7 years after initial presentation. Two patients died of unrelated causes; the remaining 20 patients are alive and well with a median follow-up of 16 (1-34) years. Differentiated thyroid cancer found incidentally at surgery for hyperthyroidism has a good prognosis.
\end{abstract}

Keywords: thyroid neoplasms; thyrotoxicosis; thyroidectomy

Previous studies have suggested that thyroid cancer occurs more frequently in patients operated for hyperthyroidism than in euthyroid patients. ${ }^{1-4}$ The reported incidence of thyroid carcinoma found at surgery in hyperthyroid patients ranges from $0.21 \%$ to $8.7 \%$ depending on the criteria used to select patients for surgery, patient characteristics and history of previous neck irradiation. More recently, it has been suggested that thyroid cancer associated with Graves' disease is highly aggressive and should be treated vigorously. ${ }^{5}$ Other investigators ${ }^{6}$ have not confirmed this finding and the issue remains controversial. We report our experience in patients found to have differentiated thyroid cancer at thyroidectomy for hyperthyroidism.

\section{Patients and methods}

Between 1949 and 1997, 986 patients with differentiated thyroid cancer were treated at the Royal Marsden Hospital, which serves as a tertiary referral unit for patients with thyroid disease. Twenty-three patients (19 women, four men, median age at diagnosis 35 years, range 21-78 years) had presented with clinical features of hyperthyroidism. The duration of hyperthyroidism ranged from 4 months to 13 years (median 3 years). Graves' disease was diagnosed in 11 patients based on clinical findings, the presence of circulating thyroid antibodies and a uniformly increased ${ }^{131}$ I thyroid uptake scan appearance.

Toxic multinodular goitre was diagnosed in eight patients and autonomously functioning thyroid adenoma in four patients based on clinical and scan appearances. Graves' disease with a palpable nodule was not diagnosed in this series.

Subtotal thyroidectomy was performed initially in all cases. Indications were: recurrent hyperthyroidism after medical treatment (7), physician preference (5), large goitre responding poorly to medical treatment (4), persistent drug effects (3), enlarging nodule (2) and patient preference (2). In 13 patients, total thyroidectomy was subsequently performed followed by $3 \mathrm{GBq}$ of ${ }^{131} \mathrm{I}$ to ablate residual tissue.

All patients were followed-up according to our thyroid cancer protocol at intervals increasing from 6 months to yearly. At each visit, patients were clinical assessed and serum thyroglobulin was estimated. Where whole body ${ }^{131}$ I scans demonstrated persistent uptake, further ablation with radioiodine was given.

\section{Results}

Eighteen papillary, four follicular and one Hurthle cell carcinoma were found incidentally in the thyroidectomy specimens. In three cases, more than one focus of cancer was identified. Tumour size ranged from $4 \mathrm{~mm}$ to $5.5 \mathrm{~cm} ; 12$ tumours were less than $1 \mathrm{~cm}$ (T1), five were $1-2 \mathrm{~cm}$ and five were over $2 \mathrm{~cm}$ in diameter. Five $(45 \%)$ of the tumours in the Graves' patients, two $(50 \%)$ in the toxic adenoma patients and four $(57 \%)$ in the multinodular patients were over $1 \mathrm{~cm}$ in diameter. Only one patient had evidence of lymph node involvement at presentation.

Follow-up ranged from 1-34 years with a median of 16 years. Two patients suffered a local recurrence; one with associated Graves' disease, the other with an underlying multinodular goitre. A $2.5 \mathrm{~cm}$ follicular thyroid cancer was discovered at thyroidectomy in the Graves' patient. She underwent total thyroidectomy and received ablative radioiodine but despite this, developed lymph node recurrence 5 years after presentation. Block dissection of 
lymph nodes was performed but two years later she had developed brain metastases and died 7 years after initial diagnosis.

The patient with multinodular goitre and recurrent thyroid cancer had been found to have an $8 \mathrm{~mm}$ Hurthle cell carcinoma at the time of subtotal thyroidectomy. Ten years later a $1 \mathrm{~cm}$ palpable nodule was discovered in the thyroidectomy scar and was found to contain recurrent cancer. She underwent completion total thyroidectomy. She remained disease-free thereafter and died of heart disease 17 years after initial presentation with no evidence of recurrent thyroid cancer at death.

There was one further death in a patient with associated Graves' disease unrelated to thyroid cancer (gall bladder cancer). The remaining 20 patients are alive and well with no evidence of recurrent disease.

\section{Discussion}

In this series of patients with occult thyroid malignancy and hyperthyroidism, we have not found evidence of increased tumour aggressiveness over a long period of follow-up. Only two patients developed local recurrence and only one distant metastases. Tumours in patients with Graves' disease were no larger than in other hyperthyroid patients and behaved no differently from those in non-Graves' patients. These results contrast with those of Belfiore $e t a \bar{P}$ who reported a high incidence of local invasiveness, lymph node involvement and distant metastases in their patients with Graves' disease and thyroid cancer. However, all but two of their Graves' patients had palpable nodules in contrast to the present study (none had nodules) which could indicate that tumours in the previous study were detected later and hence had a poorer outcome.

Only three patients had evidence of multiple foci in histological specimens. A higher frequency may have been found if all patients had

1 Sokal JE. Incidence of malignancy in toxic and nontoxic nodular goitre. $\mathcal{F} A M A$ 1954;154:1321-5.

2 Shapiro SJ, Friedman NB, Perzik SI, Caty B. Incidence of thyroid carcinoma in Graves' disease. Cancer 1970;26:126170 .

3 Farbota LM, Calandra DB, Lawrence AM, Paloyan E. Thyroid carcinoma in Graves' disease. Surgery 1985;98:1148 roid

4 Pacini F, DiCoscio GC, Anelli S, et al. Thyroid carcinoma in thyrotoxicosis patients treated by surgery. $\mathcal{F}$ Endocrinol Invest thyrotoxicosis pat

5 Belfiore A, Garofalo MR, Giuffrida D, et al. Increased aggressiveness of thyroid cancer in patients with Graves' disease. F Clin Endocrinol Metab 1990;70:830-5.

\section{Learning points}

- tumours discovered incidentally at thyroidectomy in patients with thyrotoxicosis generally have a good prognosis

- occult thyroid tumours in patients with Graves' disease behaved no differently from those in non-Graves' patients

undergone total thyroidectomy. Similarly, elective node dissection on all patients may have detected a higher incidence of nodal involvement. Nevertheless, the prognosis of our patients remained good and certainly we would have expected to detect metastases during the long period of follow-up.

The good outcome of the patients in our series is similar to that found in previous studies. ${ }^{6-8}$ Possible factors contributing to the high survival and low incidence of recurrences include young age at presentation and more aggressive treatment. In this series, we treated patients with less favourable prognostic indicators (older patients, T2 and T3 tumours) with more radical surgery and ablative iodine. However, treatment alone does not explain the initial lack of invasiveness and metastases observed in this study.

Care is needed in interpreting histology as the diffusely hyperplastic gland of Graves' disease may simulate malignancy; the cases in this series were all diagnosed by experienced pathologists according to established criteria. ${ }^{9}$

In summary, our results do not suggest increased aggressiveness in incidentally discovered thyroid carcinomas associated with hyperthyroidism. Further work is needed to define the optimal treatment for this group of patients.

6 Hales IB, McElduff A, Crummer P, et al. Does Graves' disease or thyrotoxicosis affect the prognosis of thyroid cancer? f Clin Endocrinol Metab 1992;75:886-9.

7 Dobyns BM, Sheline GE, Workman JB, Tompkins EA, McConaley WM, Becker DV. Malignant and benign neoplasms of the thyroid in patients treated for hyperthyroidism. F Clin Endocrinol Metab 1974;38:976-998.

8 Behar R, Arganini M, Wu TC, McCormick M, Straus FH, DeGroot LJ. Graves' disease and thyroid cancer. Surgery DeGroot LJ. Graves'

9 Rosai J, Carcangiu ML, Delellis RA. Atlas of tumour patholRosai J, Carcangiu series, Fascicle 5, Tumours of the thyroid gland.
ogy, 3rd Washington: Armed Forces Institute of Pathology,1992; $\mathrm{p}$ 302 . 